MATEC Web of Conferences 6, 01007 (2013)

DOI: $10.1051 /$ matecconf/20130601007

(C) Owned by the authors, published by EDP Sciences, 2013

\title{
Effect of compressive loading on the risk of spalling
}

\author{
H. Carré ${ }^{1}$, P. Pimienta ${ }^{2}$, C. La Borderie ${ }^{1}$, F. Pereira ${ }^{1,2}$ and J.-C. Mindeguia ${ }^{3}$ \\ 1 SIAME EA-4581, Sciences pour l'Ingénieur Appliquées à la Mécanique et au génie \\ Électrique, University of Pau, Anglet, France \\ ${ }^{2}$ CSTB, Université Paris-Est, Centre Scientifique et Technique du Bâtiment (CSTB), \\ Marne la Vallée, France \\ ${ }^{3}$ I2M / Environmental and Civil Engineering Dept, University of Bordeaux, France
}

\begin{abstract}
Mechanical loading is an important parameter of spalling phenomenon likely to occur in concrete during heating. Several tests in laboratory have shown an increase of the risk of spalling in the compressed areas. In this study, a specific metallic frame has been developed to apply uniaxial and biaxial stresses on slabs during fire tests. Tests carried out on an ordinary concrete $\left(\mathrm{f}_{\mathrm{c} 28}=37 \mathrm{MPa}\right)$ exposed to ISO 834-1 temperature curve with several levels of uniaxial loading are presented. No spalling was observed when samples were loaded at 0,5 and $10 \mathrm{MPa}$. In the opposite, spalling was observed when the compressive stress was increased to $15 \mathrm{MPa}$.
\end{abstract}

\section{INTRODUCTION}

Several observations during fire tests show that compressive stresses can increase the risk and the amount of spalling. For columns, the level of loading during heating influences the risk of spalling [1-3]. When beams are heated when loaded in bending, spalling occurs preferentially in the compressed areas $[4,5]$. Compressive stresses are taken into account in the models by several authors [6-8] in order to describe spalling mechanism. However, laboratory results showing quantitative influence of the compressive load on spalling are few.

In this study, concrete slabs were loaded in compression parallel to their sides and exposed to the ISO 834-1 temperature curve. The tests were carried out on an ordinary concrete (B40). This concrete has been largely studied in previous researches [9-11]. Several tests are achieved with several loading levels: from 0 to $15 \mathrm{MPa}$. Measurements of temperature and gas pore pressures [12] were carried out during the tests at different depths from the heated surface. The influence of mechanical loading on the risk of spalling was observed both by observations during heating and by measuring spalling depths after cooling.

\section{DESCRIPTION OF TESTS}

\subsection{Mixes of studied concretes and sample preparation}

The chosen mix is then representative of ordinary concrete used in common civil structures. It is called B40 in the rest of the document. Its formula and some mechanical properties are given in Table 1.

Slabs were casted in the laboratory. Their dimensions were: $58 \mathrm{~cm} \times 68 \mathrm{~cm} \times 15 \mathrm{~cm}$. Before testing, the slabs were kept in a climatic room at $20^{\circ} \mathrm{C} \pm 2{ }^{\circ} \mathrm{C}$ and $50 \% \mathrm{RH} \pm 5 \% \mathrm{RH}$. The mean water content

This is an Open Access article distributed under the terms of the Creative Commons Attribution License 2.0, which permits unrestricted use, distribution, and reproduction in any medium, provided the original work is properly cited. 
MATEC Web of Conferences

Table 1. Mixes of the studied concretes.

\begin{tabular}{|l|c|c|l|c|}
\hline \multicolumn{1}{|c|}{ Component } & Unity & B40 & \multicolumn{2}{c|}{ Mechanical properties } \\
\hline Cement CEM II/A-LL 42.5 R PM-CP2 (C) & $\mathrm{kg}$ & 350 & 28 days compressive strength & $37 \mathrm{MPa}$ \\
\hline 8/12.5 calcareous gravel & $\mathrm{kg}$ & 330 & 28 days modulus of elasticity & $36 \mathrm{GPa}$ \\
\hline 12.5/20 calcareous gravel & $\mathrm{kg}$ & 720 & 28 days tensile strength & $2.4 \mathrm{MPa}$ \\
\hline 0/2 siliceous sand (Chazé) & $\mathrm{kg}$ & 845 & & \\
\hline Water (W) & $\mathrm{kg}$ & 188 & & \\
\hline Superplasticizer & $\mathrm{kg}$ & 3.5 & & \\
\hline
\end{tabular}

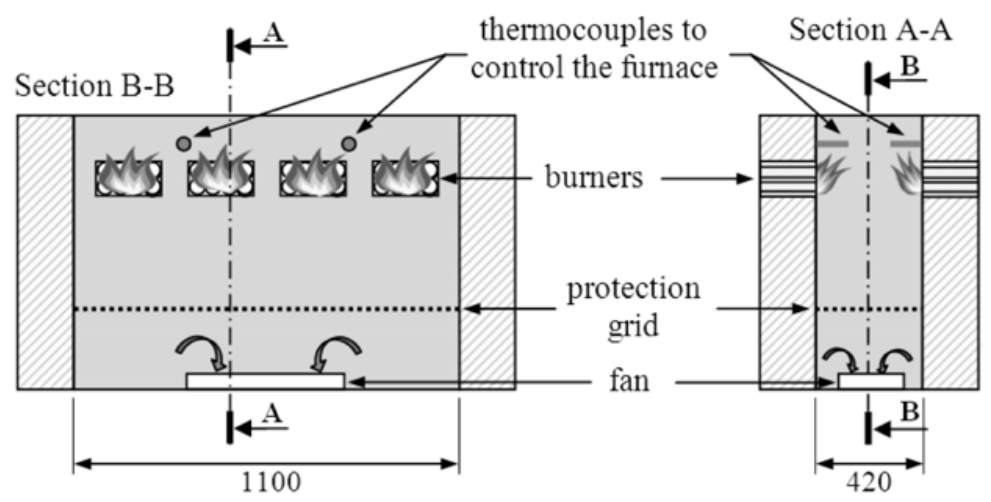

Figure 1. Furnace (2 vertical sections).

before the tests was approximately $3.8 \%$. Fire tests were carried out when the age of the specimens was greater than 90 days.

\subsection{Measurements during heatings}

Five slabs were equipped with gauges allowing to measure at the same point temperature and gas pore pressure. The devices are the same that the ones described in [12]. Slab ${ }^{\circ} 1$ was equipped by thermocouples tied at different depths. Table 2 in section 2.4 presents how each slab is instrumented.

\subsection{Experimental device}

Figure 1 shows the furnace used to carry out the tests. It is equipped with 8 gas burners. The tested sample is placed on the top of the furnace, horizontally. In order to apply an horizontal mechanical load, a steel frame was designed (see Fig. 2). The load is applied with 2 flat jacks (type Freyssinet). The device allows to apply uniaxial (with 2 flat jacks) or biaxial loading (with 4 flat jacks). Only the tests with uniaxial loading are presented here.

The slabs are hanged with the suspension system and the position is chosen to guarantee the correspondence between the mean plane of the slabs and the loading axis of the jacks.

The flat jacks were calibrated and the sensitivity to the implementation of the device (flat jacks, metallic charge transfer profile, slab...) was studied. The flat jacks showed good linearity (relationship between the pressure in the jack and the applied load) and a very good repeatability. The difference between the measurements with the established law is less than $\pm 2 \%$.

To assess the state of stress in the slab when mechanical load is applied, strain gauges were glued on the surfaces of a slab of reference. Three strain gauges were bonded on each main face, face-to-face, parallel to the applied load (see Fig. 3, in the left hand). The slab was installed in the test apparatus and 


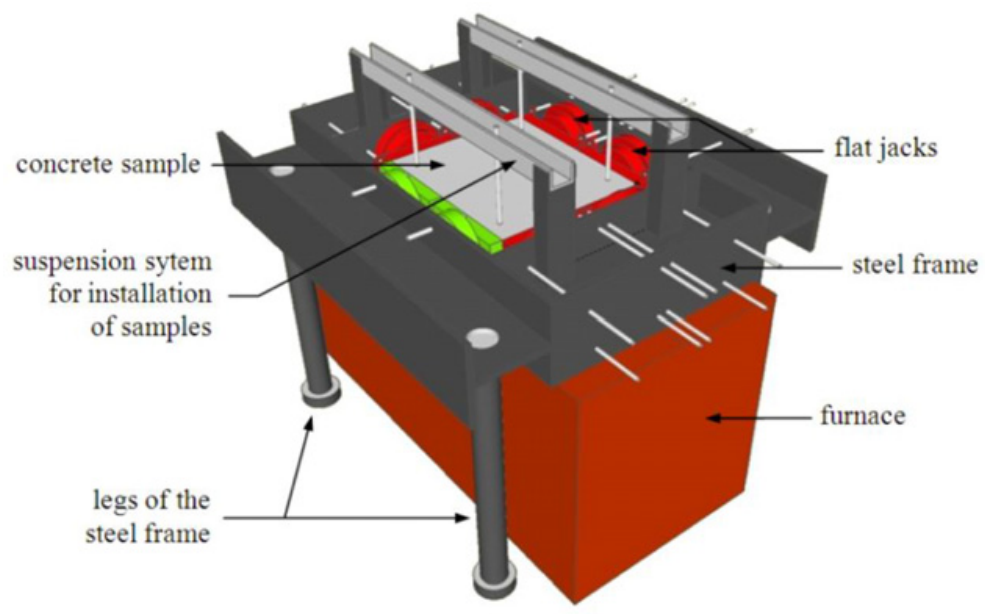

Figure 2. Furnace and frame for mechanical loading.
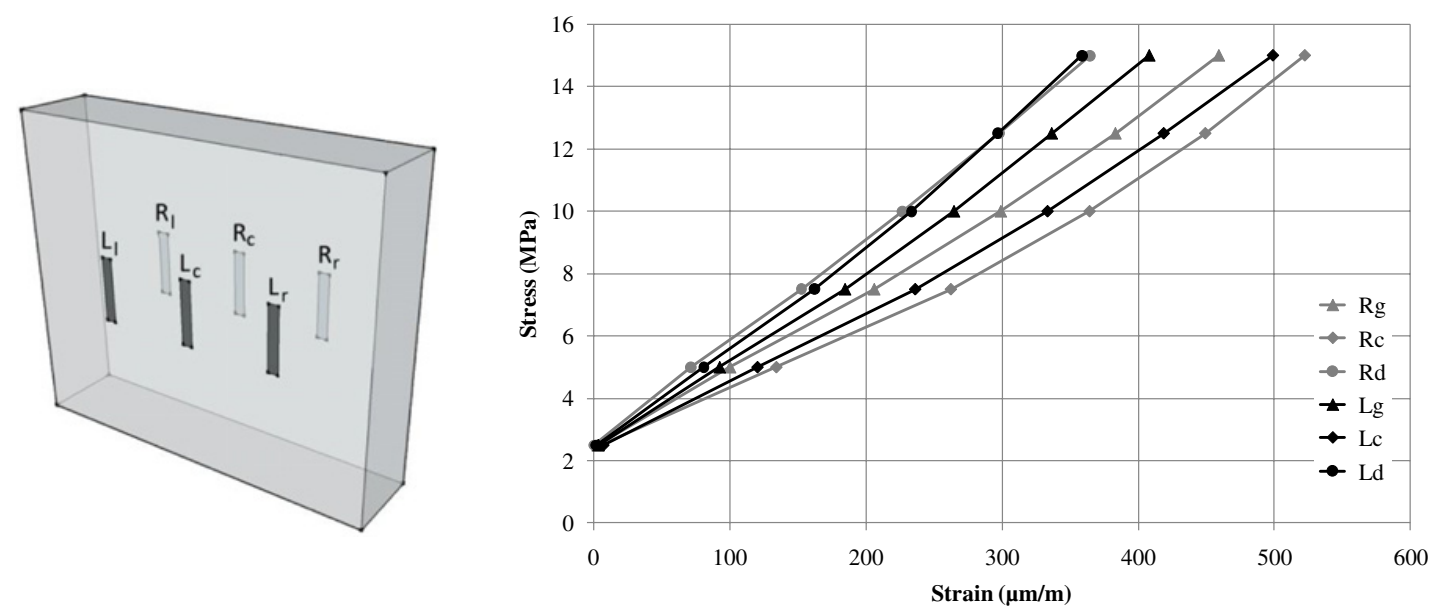

Figure 3. Position of strain gauges in slab of reference (left hand) - relation between strains and applied stress.

strains were recorded for different load levels. Figure 3 shows the results obtained with the strain gauges. Although the results are quite scattered, they were considered satisfactory compared to the dispersion of deformations measured during compression test on cylinder with an extensometer (for determining the modulus of elasticity of concrete) which is commonly of the order of 10 to $20 \%$.

\subsection{Experimental program}

Six slabs of B40 were tested with different stress levels: 0, 5, 10 and $15 \mathrm{MPa}$. The slabs were exposed to an ISO 834-1 fire test for 2 hours. Table 2 presents, for each test, the level of loading, the measuring devices: pressure sensors $(\mathrm{P})$ and thermocouples (TC). During the test, the pressure in the jacks is not changed. he amount of oil remains constant. The load level given in Table 2 corresponds to the initial loading, before heating. 
Table 2. Test program and slabs equipment.

\begin{tabular}{|c|c|c|c|c|c|}
\hline $\mathrm{N}^{\circ}$ & $\begin{array}{c}\text { Applied compressive } \\
\text { stress (MPa) }\end{array}$ & TC & Depth TC* $(\mathrm{mm})$ & $\mathrm{P}$ & Depth P* (mm) \\
\hline 1 & 0 & YES & $10,25,40,60,80,120,140$ & NO & \\
\hline 2 & 5 & YES & $10,20,30,40$ & YES & $10,20,30,40$ \\
\hline 3 & 10 & YES & $10,20,30,40$ & YES & $10,20,30,40$ \\
\hline 4 & 10 & YES & $10,20,30,40$ & YES & $10,20,30,40$ \\
\hline 5 & 15 & YES & $10,20,30,40$ & YES & $10,20,30,40$ \\
\hline 6 & 15 & YES & $10,20,30,40$ & YES & $10,20,30,40$ \\
\hline
\end{tabular}

* Distance from the heated surface.

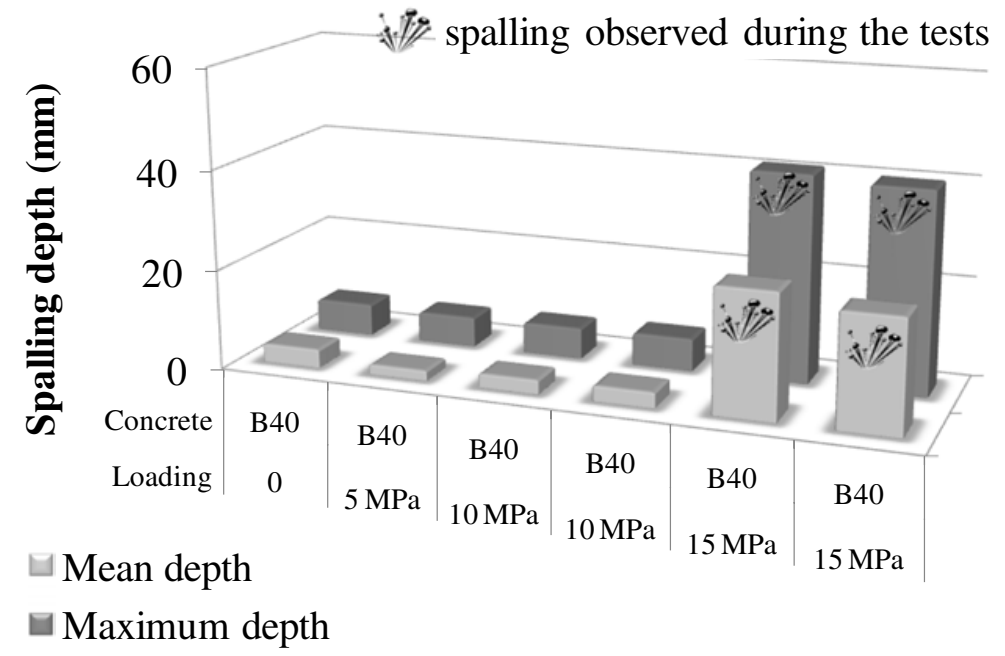

Figure 4. Mean and maximum spalling depth measured one day after the test.

\section{RESULTS AND DISCUSSION}

\subsection{Observation and measure of spalling}

The influence of the applied compressive load on spalling is presented in Figure 4. Maximum spalling depth and mean spalling depth were measured one day after the test and are plotted versus the applied compressive stress. The occurrence of spalling in the slabs is shown in the graph by a symbol.

An edge effect on spalling depths has been clearly observed on the heated slabs. Therefore, mean and maximum spalling depths have been calculated by excluding $8 \mathrm{~cm}$ wide strip along the edges. It should be noted that even in the absence of spalling during heating, spalling depth measurements one day after the test is non-zero. Indeed, 2 hours heating led to a very significant damage of the exposed surface and a loss of material during cooling.

The influence of the compressive loading is clearly visible in the Figure 4 . The slabs loaded at 0,5 and $10 \mathrm{MPa}$ showed no spalling during the tests. On the contrary, significant spalling was observed on the 2 slabs loaded at $15 \mathrm{MPa}$.

Important sounds of explosions were heard during the two last tests. These noises were heart between 20 and 23 minutes and between 17 and 25 minutes respectively for the tests $n^{\circ} 5$ and $n^{\circ} 6$ respectively. Figure 5 shows photographs of one of the two slabs after cooling. The spalling is clearly visible. 
IWCS 2013

Table 3. Maximum gas pore pressure and corresponding temperature.

\begin{tabular}{|c|c|c|c|c|c|}
\hline Test & Load (MPa) & P10 max / T10 & P20 max / T20 & P30 max / T30 & P40 max / T40 \\
\hline 2 & 5 & $0.93 / 263$ & $0.67 / 210$ & $1.05 / 186$ & $0.31 / 337$ \\
\hline 3 & 10 & $0.65 / 153$ & $0.37 / 128$ & $0.30 / 121$ & $0.69 / 156$ \\
\hline 4 & 10 & $0.94 / 270$ & $0.16 / 135$ & $0.25 / 183$ & $0.73 / 159$ \\
\hline 5 & 15 & $0.56 / 292$ & $0.30 / 169$ & $0.43 / 165$ & - \\
\hline 6 & 15 & $0.38 / 278$ & $0.53 / 160$ & $0.27 / 152$ & - \\
\hline
\end{tabular}
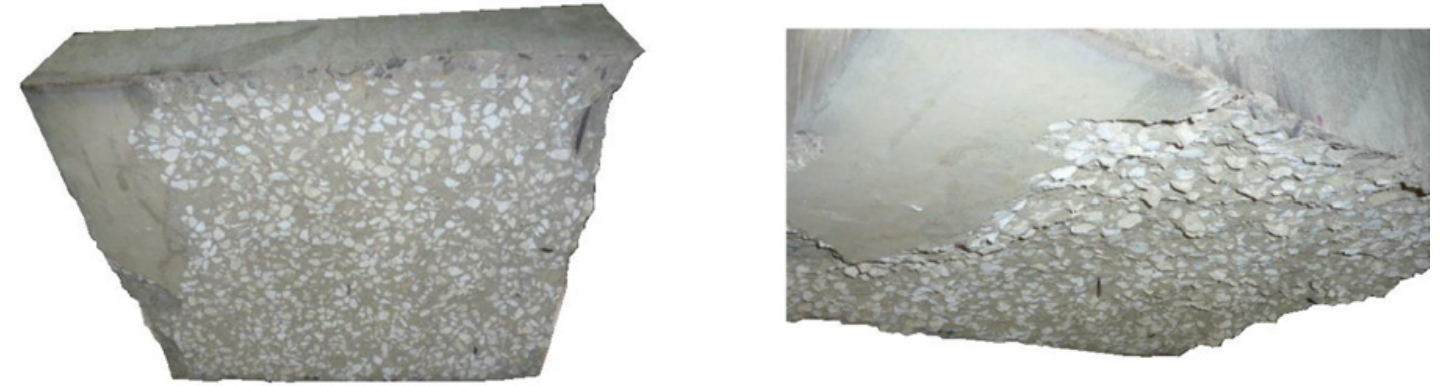

Figure 5. Heated face of the slab $n^{\circ} 5$ after cooling (applied load: $15 \mathrm{MPa}$ ).
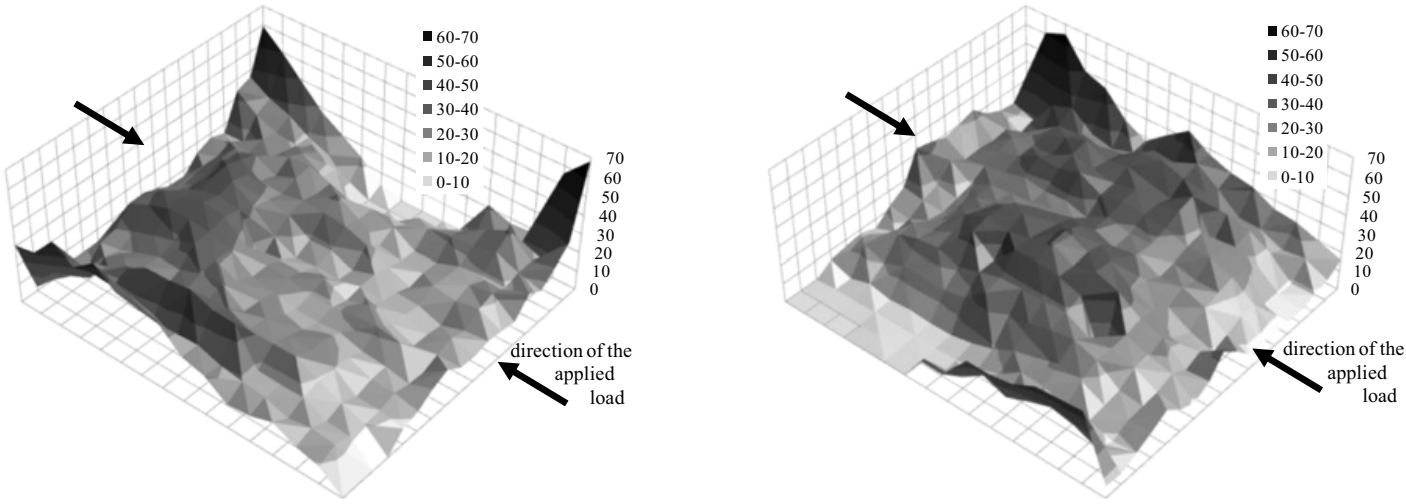

Figure 6. Topography of the heated face of the slabs 5 and 6 after cooling.

After cooling, the topography of the heated face of slabs 5 and 6 was measured with a mesh size of $4 \mathrm{~cm}$ in both directions of the plane. It should be noted that spalling was much larger in 5 of the angles: 2 angles for the test 5 and 3 for the test 6 . Spalling appears fairly evenly distributed in the central part of the slabs (surface excluding $8 \mathrm{~cm}$ wide strip along the edges).

\subsection{Temperature and gas pore pressure}

Pore gas pressure was measured at 10 (P10), 20 (P20), 30 (P30) and 40 (P40) mm from the heated surface. The maximum gas pore pressures and the temperatures measured in the same location and at the same time are given in Table 3.

Figure 7 shows the gas pore pressure change during the test. In the graphs on the left, pressures are plotted versus the time, on the right they are plotted versus the temperature measured in the same location. Both graphs are complementary. First type of graph allows examining the pressure changes 
MATEC Web of Conferences
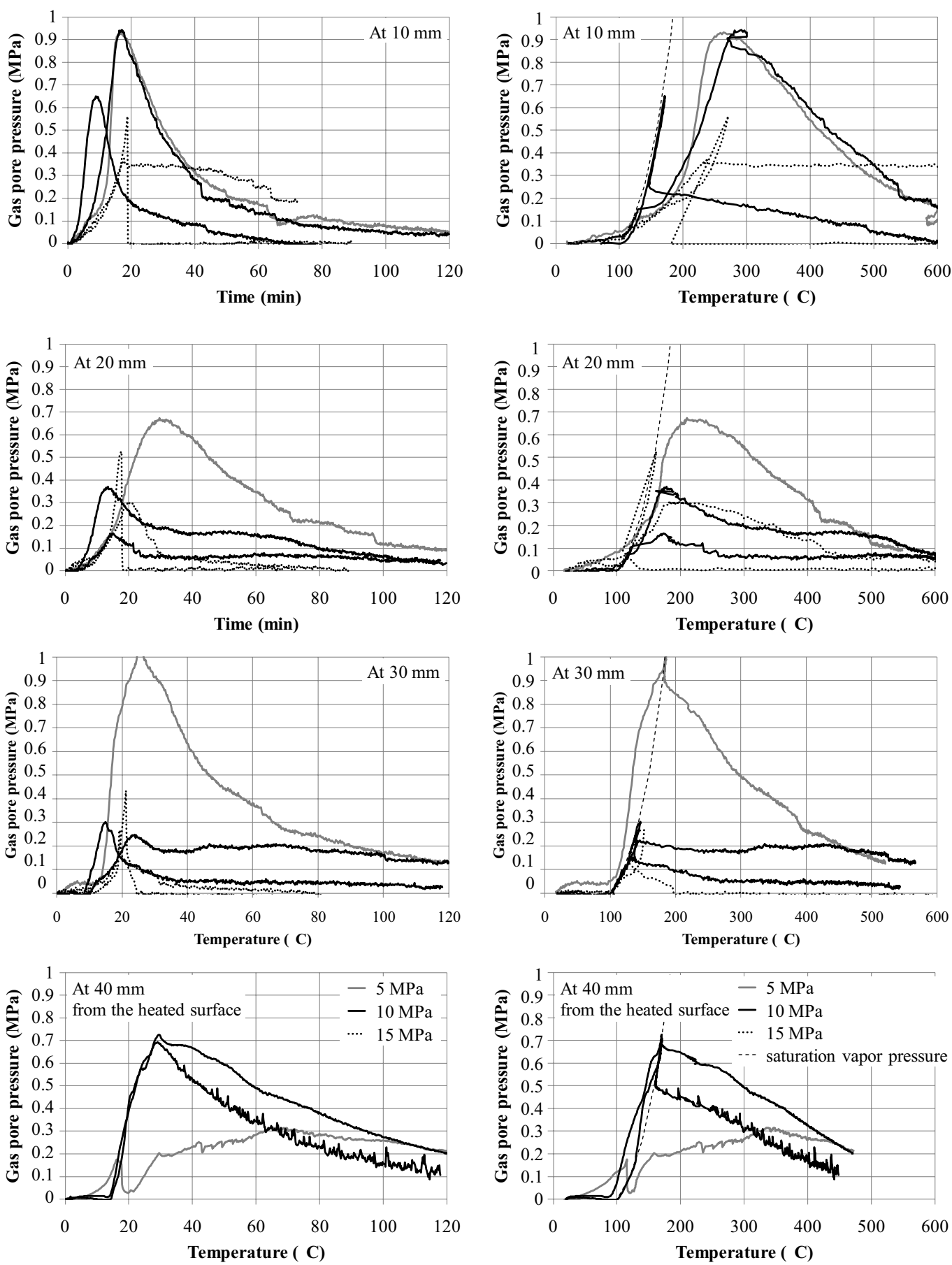

Figure 7. Variation of gas pore pressure versus temperature.

during the test. Second type of graph allows particularly comparing the recorded curves with the saturation vapor pressure curve.

By analyzing these graphs, we can make the following comments. 
IWCS 2013

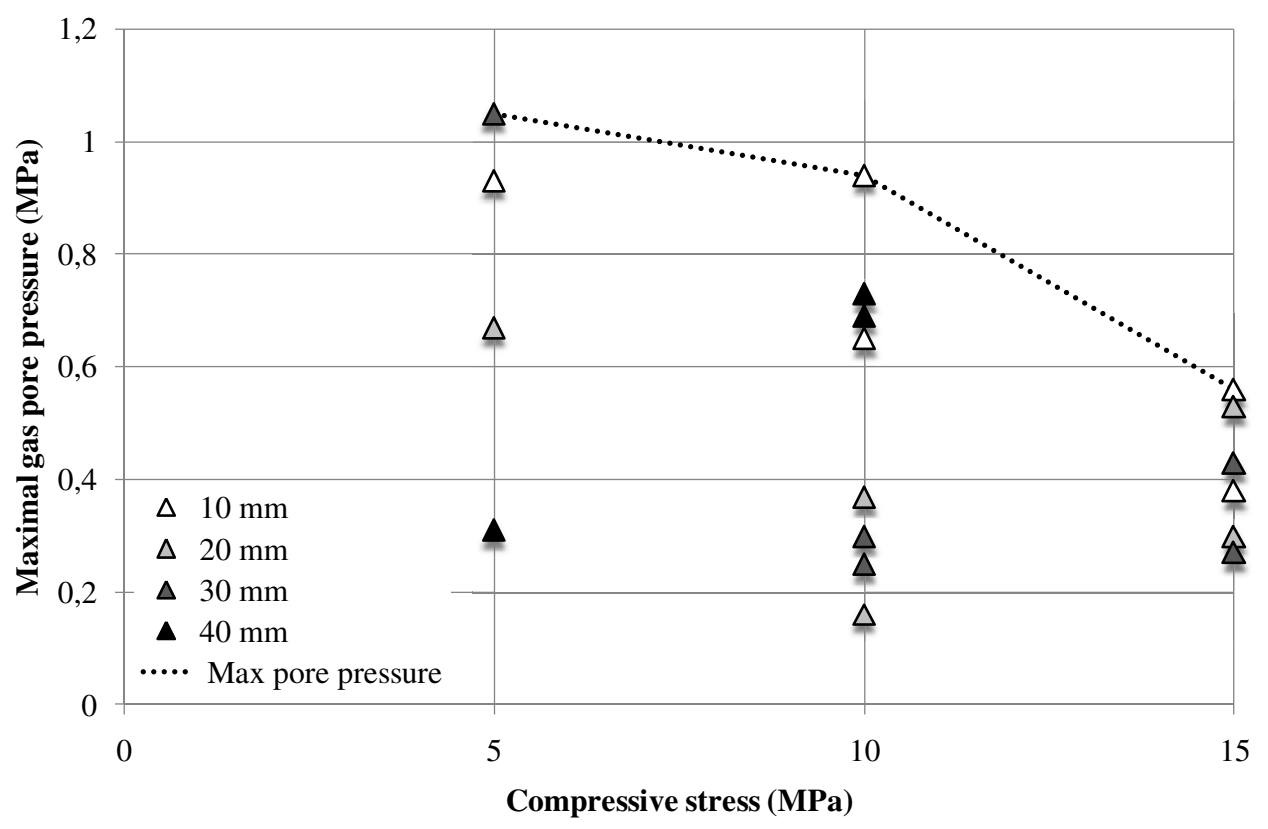

Figure 8. Maximum pore gas pressure versus the applied stress and the measuring depth.

In test $\mathrm{n}^{\circ} 5(15 \mathrm{MPa})$, the pressure drop which match to the spalling event can be clearly observed at the time $19 \mathrm{~min}$ at 10, 20 and $30 \mathrm{~mm}$ depths. Spalling certainly occurred in the area where gauges were located.

In test $\mathrm{n}^{\circ} 6(15 \mathrm{MPa})$, the pressure does not drop. However, after $17 \mathrm{~min}$, the curve stops to increase, follows a plateau and then decreases after $40 \mathrm{~min}$.

Analyses of the graphs presented on the right show that curves recorded at 20, 30 and $40 \mathrm{~mm}$ closely follow the saturation vapor pressure curve. By opposite, all the curves measured at $10 \mathrm{~mm}$ except one $(10 \mathrm{MPa})$ are different. Explanation has not been found to explain this result.

An overpressure is visible on a curve recorded at $30 \mathrm{~mm}$ (5 MPa). Kalifa and al [12] have reported overpressure in their tests. It has been attributed to partial pressure of the air enclosed in the porous network. The measured overpressure in this test could be significant.

No clear influence of the applied compressive stress on the increasing part of the curves by comparing recorded curves at 20,30 and $40 \mathrm{~mm}$ has been found. The following question which could be raised would be: does the applied stress can affect the time when the gas pore pressure stops to increase and has a bias away the saturation vapor pressure curve?

Applied compressive stress could affect the maximum pressure in two ways. Either, the applied stress could delay the pressure decrease by making the material more compact and then delaying its permeability increase. Either, and by opposite, the applied stress could move forward the pressure decrease by accelerating concrete cracking and then increasing the permeability.

Maximum pore gas pressure versus the applied stress and versus the measuring depth is plotted in Figure 8. The first conclusion that we can draw from this graph is that there is no clear relationship between the applied compressive stress and the measured gas pore pressure. However, we can observe the following trend: maximum pressure decreases when compressive stress increases. This could be explained by an increase of the permeability when compressive stress increases. The second and main conclusion is that there is not a direct relationship between the measured spalling (spalling was observed when applied stress was $15 \mathrm{MPa}$ ) and the measured maximum gas pore pressure. 


\section{MATEC Web of Conferences}

This result is in good agreement with previous researches presented in [13]. From their observations, authors have concluded that no clear link exists between gas pore pressure and concrete spalling, contrarily to most of the known simulations. Some of the testing configurations leading to low measured pressures showed concrete spalling while other configurations leading to very high pressures did not show any spalling. Then, authors assumed that gas pore pressure is not the only physical driving force for concrete spalling.

\section{CONCLUSIONS AND FUTURE OUTLOOK}

In this study, an experimental device has been designed. It allows to apply mechanical load on slabs while one of their main face is heated in a furnace. Loading induced compressive stress in the plane of slabs in an uniaxial pattern. The state of stress generated in the sample was assessed. Although the results showed some dispersion across the slab, they were satisfactory.

The first results with uniaxial loading tests on slabs made with an ordinary concrete B40 have been presented. Four load levels were applied. The effect of mechanical compressive loading on the risk of spalling has been highlighted. There were no spalling for mechanical loading lower than $10 \mathrm{MPa}$. Spalling was observed for compressive stress of $15 \mathrm{MPa}$.

The analyze of the gas pore pressure curves did not showed clear influence of the applied compressive stresses on the increasing part of the curves. There is no clear relationship between the applied compressive stress and the maximum measured gas pore pressure. However, we can observe the following trend: maximum pressure decreases when compressive stress increases. This could be explained by an increase of the permeability when compressive stress increases. The second and main conclusion is that there is not a direct relationship between the measured spalling and the measured maximum gas pore pressure.

The device is designed to apply uniaxial but also biaxial loading. The influence of a biaxial compressive loading on the risk of spalling will be studied. The behavior of high performance concrete (compressive strength at 28 days higher than $60 \mathrm{MPa}$ ) will also be studied. Numerical simulations will be useful to better interpret the results and to better understand the combined effects of the gas pressure in the pores and the thermo-mechanical stresses.

\section{References}

[1] Alia F., Nadjaia A., Silcocka G., Abu-Tair A., Outcomes of a major research on fire resistance of concrete columns, Fire Safety Journal 39 (2004) 433-445

[2] Ali F., Nadjai A., Choi S., Numerical and experimental investigation of the behavior of high strength concrete columns in fire, Engineering Structures 32 (2010) 1236-1243

[3] Benmarce A., Guenfoud M., Behaviour of axially restrained high strength concrete columns under fire, Construction and Building Materials 2005, 57(5) 283-287

[4] Sullivan, Patrick JE. A probabilistic method of testing for the assessment of deterioration and explosive spalling of high strength concrete beams in flexure at high temperature. Cement and Concrete Composites 2004;26:155-62

[5] Pimienta P., Pardon D., Mindeguia J.-C;. Fire behaviour of high performance concrete - An experimental investigation on spalling risk. Sixth Intrenational Confernce on Structures in Fire (SiF'10). DEStech Publications Inc. Edited by Venkatesh Kodur and Jean, marc Franssen. East Lansing, Michigan, 2010 June $1^{\text {st }}-3^{\text {rd }}$. pp 880-889

[6] Zhukov., Explosive failure of concrete during a fire (in Russian), Translation No. DT 2124, Joint Fire Research Organisation, Borehamwood, 1975.

[7] Bazant, Z. P. et M. F. Kaplan, Concrete at High Temperatures: Material Properties and Mathematical Models, Pearson Education (1996) 
[8] Sercombe J., Galle C., Durand S.F., Bouniol P., On the importance of thermal gradients in the spalling of high-strength concrete, 14th engineering mechanics conference Austin, USA, (2000)

[9] Mindeguia J-C, Pimienta P., Carré H., La Borderie C., "On the influence of aggregate nature on concrete behaviour at high temperature", European Journal of Environmental and Civil Engineering, Vol. 16, n², February 2012, 236-253

[10] Mindeguia J-C, Hager I., Pimienta P., Carré H., La Borderie C., Parametrical study of transient thermal strain of ordinary and high performance concrete, Cement and Concrete Research, vol. 48, 2013, pp. 40-52

[11] Mindeguia J.C., Pimienta P., Carré H., La Borderie C., "Experimental analysis of concrete spalling due to fire exposure", European Journal of Environmental and Civil Engineering, 2013

[12] Kalifa P., Menneteau F. D., and Quenard Q, "Spalling and pore pressure in HPC at high temperature", Cement and Concrete Research 1, 1915-1927 (2000)

[13] Mindeguia J.C., Pimienta P., Carre H., La Borderie C., Experimental analysis of concrete spalling due to fire exposure. European Journal of Environmental and Civil Engineering, Published online: 17 Apr 2013, April 2013, 14 p. 